\title{
RELIGIÃO E MÚSICA: variações em busca de um tema
}

\author{
Manuel Vicente Ribeiro Veiga Junior*
}

\begin{abstract}
Música se relaciona com religião de várias maneiras, quer nos sistemas de crença, quer no controle do poder. Ambas são universais da cultura. Como não temos conhecimento dos universais empíricos da própria música, o estudo abrangente de sua associação com o sagrado é um duplo desafio. Concentrando-se no homem e para entendê-lo melhor, optou-se pela busca de origens possivelmente comuns, um processo que não enfatiza os monumentos musicais das religiões propriamente ditas e dos caminhos de salvação, Ocidente e Oriente não esquecidos. A volta ao passado mais remoto, aos milênios em que sons humanamente organizados se articularam em símbolos, é o ponto crucial. Os ângulos, as concepções, as revisões e os métodos de abordagem da parca evidência disponível constituem as variações de nosso título. Do ponto de vista etnomusicológico, as questões que ressurgem não são sobre que tipo de música foi feita, nem sobre os processos pelo quais a música foi primeiramente criada, mas as razões, isto é, sua necessidade de existência (suas funções).

PALAVRAS-CHAVE: Religião e música. Origens e funções. Modelos. Instrumentos.
\end{abstract}

E eis que, ante a infinita Criação, O próprio Deus parou, desconcertado e mudo! Num sorriso, inventou o Homo sapiens, então, Para que lhe explicasse aquilo tudo...

(Mário Quintana, Espelho mágico, XXVIII, 1975)

\section{INTROITUS ET CONFITEOR}

Pode-se imaginar quão mais difícil é para os teólogos do que para os poetas explicarem por que um ou vários deuses criaram o homem e ele necessita ser salvo. Por quê? Do quê? Para quê? Como? Não menos espinhosa é a dúvida se deuses criam o homem, ou se é o homem quem inventa Deus, ou deuses, até à sua imagem e semelhança. É possível que conheçamos o homem melhor, por sermos um deles; não tanto o Deus ou os deuses, que podem ou devem, se quiserem, estar longe de nós, do outro lado, o do sagrado, o do "inteiramente outro", indescritíveis em termos comuns. O homem, entretanto, sente necessidade de religião, de ir além de si próprio para que não arque sozinho com a sustentabilidade do mundo e da vida (e morte) que compartilha aparentemente como outros seres e o sagrado. Também faz música.

\footnotetext{
* Doutor em Etnomusicologia. Professor emérito da Universidade Federal da Bahia - UFBA. Membro da Academia Brasileira de Música.

Rua: Basílio da Gama, s/n - Campus Universitário do Canela. Cep: 40110-140. Salvador - Bahia - Brasil. mveiga@ufba.br
}

As variações que se seguem penderão mais para o homem do que para os deuses, mais para o elementar do que para o transcendente, mais para a música do que para a religião, embora buscando vínculos entre elas. Eventualmente, uma busca das origens pode propiciar uma ideia mais depurada da natureza de ambas. O procedimento reverso, inevitavelmente especulativo, pode conter petições de princípio diante da indefinição e da carência de documentação que temos. Implica também a adoção de uma escala evolutiva que nem é linear, já sabemos, tampouco necessariamente procede do mais simples para o mais complexo.

Música e religião são ambas universais da cultura. Ter música como um universal reflete a presença, em qualquer cultura, de algo parecido com o que, em nossa opinião, chamamos de música. Mas não temos uma escala para medir semelhanças e diferenças. Há grupos humanos tão despojados que não têm instrumentos musicais, mas fazem do corpo instrumento para sua música. Por outro lado, ainda desconhecemos os universais empíricos da própria música, isto é, não temos uma definição do necessário e suficiente para que 
um evento que envolva sons, ruídos e pausas seja música, e nada mais do que música. Ainda que se limite o evento musical ao "humanamente organizado", ainda temos de admitir que os recortes podem ser bastante variados.

“O som é uma expressão universal”, diz o psicomusicólogo Houshang Khazrai (1986, p. 145). E continua:

A natureza se exprime, entre outros instrumentos, pelo som. O mundo é um universo complexo das ondas rítmicas cujo som constitui uma delas, assumindo o papel da expressão tanto verbal (no caso do homem) quanto não verbal (no caso do homem, dos animais e, provavelmente, dos vegetais, das substâncias probiológicas e elementares ditas não vivas) (1986, p. 145).

Mas “som” apenas não é música, ele bem sabe, abrindo a porta para uma série de comunicações sonoras entre animais que, em maior ou menor grau, têm características físicas até discutivelmente assimiláveis às de música, mas que não têm a intenção de sê-lo.

Um artigo de Siegfried Nadel, de 1930, ainda ajuda a esclarecer alguns pontos. Faz-nos ver que, na investigação das origens das artes, a música ocupa um lugar peculiar. Faz-nos também considerar que, diante da dificuldade de estabelecermos limites claros, ainda assim há um pressuposto de que podemos trata-la em termos gerais. Assim, afirmou: "Podemos dizer que o material de música é artificial, uma superadição à expressão natural através do som, e assim não encontrado neste último" (p. 532). ${ }^{1}$

Também, fora de um contexto, não se pode apurar o que faz música religiosa ser tal. Não parece haver uma essência musical religiosa em si, mas apenas correlações. Música tampouco pode ser moral ou imoral, salvo pelas más companhias, principalmente de textos e meneios que não são dela. Pode ser erótica? A própria questão do tempo musical é outro enigma. Música é ela própria uma medida do tempo. Tem uma dimensão psico-

"We can say that the material of music is artificial, super addition to natural expression through sound, and so not found in this latter." lógica capaz de tornar a obra mais excelsa em ruído caso nos seja imposta, isto é, deixa de ser música quando não queremos ouvi-la. Quanto à questão do tempo e de suas formas de concebê-lo ou medi-lo, poderíamos distinguir o tempo mecânico dos relógios, dos ciclos siderais, biológicos e de degradação de elementos radioativos. O tempo musical, entretanto, parece ser capaz de criar suas próprias bolhas.

Já neste preâmbulo deve ficar claro que a interseção (melhor diria, a cooperação ou a confluência) de música com religião é duplamente complexa. Seria um quase universal da cultura, embora a afirmação seja ousada e careça de verificação. Os vastos bancos de dados da Human Relations Area Files (HRAL), ora sediados na Universidade de Yale e compilados desde 1949, são um precioso recurso para estudos transculturais (cross-cultural studies) e arqueológicos que não foram aqui explorados. Há bancos disponíveis para acesso a textos relacionados às culturas mundiais e à arqueologia. A lista de assuntos do Outline of Cultural Materials (OCM), ${ }^{2}$ a chave para entrar nesse mundo, inclui música e instrumentos musicais, sob o tópico artes, e mais de trinta entradas para crenças religiosas, práticas religiosas, organização eclesiástica e morte. Talvez correlações e estatísticas possam ser levantadas para a associação entre religião e música.

Do ponto de vista bibliográfico (enciclopédias de música, neste caso), a última edição do Music Reference and Research Materials (1997) ${ }^{3}$ destaca das enciclopédias gerais de música aquelas que agrupa para "música sacra”, os "manuais sobre hinologia" (subdivididos por denominações religiosas, dez, predominantemente cristãs) e os “índices para os hinários”. Vale destacar a Enciclopédie de la musique sacrée editada por Jacques Porte (1968-1970), assistido por um largo grupo de autoridades predominantemente francesas, com longos artigos (não definições de termos) sobre "A expressão do sagrado no Oriente, África,

${ }^{2}$ A lista é do antropólogo George Murdock e outros.

3 Uma bibliografia de bibliografias infelizmente é descontinuada à vista do enorme crescimento da informação. A quinta e última edição, já está desatualizada. 
América do Sul” (v. 1), "Tradições cristãs dos primeiros séculos aos cultos revolucionários” (v. 2), "Tradições cristãs (continuidade e fim), essência, natureza e meios da música cristã" (v. 3) e "Documentos sonoros" (v. 4), aqui comentários e fonodiscos.

Quanto à substancial categoria bibliográfica das histórias da música - embora em boa parte efêmeras - séries de obras históricas mais recentes, como as da New Oxford Historyc Music (19541990), as da Norton (1940-1966) e da Prentice-Hall (1960-...), The Prentice-Hall History of Music Series, incluem um ou outro volume para músicas de civilizações não ocidentais. Traçar um panorama mundial só é possível através de uma enorme erudição e sacrifício de detalhes. Entre os heróis, merecem destaque Curt Sachs, Marius Schneider, Walter Wiora, como veremos adiante e, mais recentemente, Roland de Candé. Poucos conseguirão ainda juntar um contexto de história universal e de antropologia numa periodização adequada, indo além de cronologias.

\section{DE GUSTIBUS NON EST DISPUTANDUM...}

O fato observável nas relações musicais entre o homem e o universo, quer nos sistemas de crenças religiosas, quer no controle do poder, é a frequência e a variedade de usos e funções associáveis à música. Nos sistemas de crença, orações, mitos e lendas, augúrios e profecias, cultos e rituais, hierarquias sacerdotais ou de funcionários, entre outros podem envolver música. No controle do poder, músicas de súplica, de cura, de propiciação de caça e de outras atividades de subsistência que requeiram assistência do sobrenatural são também necessárias: podem ser invocações dirigidas a espíritos, deuses e bruxas.

Poderíamos inferir uma maior ou menor restrição ao uso da música nos cultos, entretanto, Zwínglio a vetou. O rigor de Calvino, por exemplo, homem de formação acadêmica suficiente para elaborar uma estética coerente, reconhecia-lhe a força, mas não a incluiria na liturgia, embora não a proibisse de todo em meras práticas devocionais.
Sabe-se da dificuldade que gerou em torno da tradução dos salmos para o francês (Clément Marot e Théodore de Bèze o diriam), sendo os salmos uma das fontes principais de textos poéticos para as igrejas cristãs. A consequência desse rigor, em particular a exclusão da polifonia, é a não emergência de um repertório de música calvinista à altura do que brotaria da igreja luterana e da anglicana no mundo ocidental. Bach seria bem menor sem o coral luterano como pedestal de grandes obras.

É também previsível que a religião islâmica não favoreça a música, até mesmo julgando-a impura. Por mais difícil que seja para um infiel avaliar a influência da religião sobre a música do Islã, reconhecendo que não há uma liturgia musical que se compare à das igrejas cristãs, ele não poderia negar que o chamado dos muezins para preces, do alto dos minaretes, ou a recitação do Corão nas mesquitas lhe parecerão associações em que a entoação vocal dá realce ao texto. Se os próprios islâmicos considerariam isso música é outra história, já que a clássica música do Irã (não arábica), por exemplo, é de um alto grau de refinamento. Sufis, um ramo místico do Islã, tem música e poesia devocionais. Dervixes alcançam o êxtase rodopiando com música.

Confesso que a experiência de maior transcendência musical que tive foi produto de um longo ritual tibetano (budista), em que sons diferenciais imponderáveis (não são fenômenos acústicos externos, mas fisiológicos, produzidos por nossos ouvidos) se sobrepunham a uma recitação cultivadamente grave. Não podem ser transcritos, mas a gravação capta os elementos que os produzem, e assim o fez meu mestre, Peter CrossleyHolland, a pedido de exilados monges tibetanos do Nepal, Butão ou Siquim. Etéreos, os sons diferenciais não apenas pairavam, mas se moviam. Não há palavras para descrever música, muito menos de sistemas musicais muito distintos dos nossos, como é esse caso. Se procurasse um símile, falaria de luzes em movimento numa aurora boreal. $\mathrm{O}$ efeito é catarse.

No caso da igreja católica, não houve um só período da história da música em que o cantochão 
gregoriano não se fizesse presente. Foi a base da polifonia, como a cruz foi das catedrais. Talvez a única exceção tenha sido o Rococó, em que as missas de um Mozart foram óperas de anjos. Ainda assim, os estilos e as formas variaram. Enquanto a música ritual tibetana parecerá feia a um desavisado, a beleza pode ser um argumento de fé no cristianismo (Chateaubriand, 1802). Sinto não ter espaço para a música sacra católica, valendo-me da mordacidade de Mendelssohn para consolo:

Há tanta fala sobre música, e ainda assim tão pouco é dito. Acredito que palavras não são suficientes para tal fim, e se achasse que fossem suficientes eu finalmente não teria mais nada a fazer com música (Carta a Souchay).

Vamos ao relativismo: o contexto e a manipulação de uma mesma melodia também alteravam sua taxonomia musical. Canções até mesmo de sentido ambíguo serviram de cantus firmus de missas e canções polifônicas. A melodia de " $L$ 'homme armé", uma delas, é do século $15 .{ }^{4} \mathrm{~A}$ origem e o significado do texto são obscuros e podem ter referência a cruzadas e turcos, a São Miguel Arcanjo, ou ao nome de uma taverna popular. A melodia, pelo contrário, é claramente cinzelada. A longa lista de compositores que a usaram vai de Dufay a Carissimi, passando por Palestrina e ainda chega a Ernst Widmer. O profano se purificava no processo composicional, ou não se considerava música e texto inseparáveis na canção:

O homem armado, o homem armado. Deve-se temer o homem armado. Já se advertiu por toda parte que cada um se venha armar de uma cota de malhas de ferro. ${ }^{5}$

${ }^{4}$ Não era novidade. Os motetos politextuais do século XIII já combinavam um cantus firmus litúrgico com vozes adicionais em latim e (ou) francês. São hoje designados pelo incipit de cada texto, na ordem das vozes. Um exemplo: Pucelete - Je languis - Domino. O primeiro é uma "cantada" em grande estilo a uma mocinha virgem bonitinha, agradável e deliciosa... O segundo é uma queixa pelo mal do amor, antes matasse... O terceiro é o tenor Domino, do "Haec dies" do gradual da missa de Páscoa: Haec dies quam fecit Domimus ["Este é o dia que o Senhor fez"], reduzido a uma única sílaba do melisma do gradual. No fim das contas, tudo era amor, cortês ou mais que isso...

${ }^{5}$ L'homme armé, l'homme armé. L’homme armé doibt on douter. On a fait partout crier que chascun se viegne armer d'un haubregon de fer. [Cortei algumas repetições]
Que tem isso a ver com o tratamento musical polifônico do ordinário da missa? Ajudou-a, entretanto, a ser tratada como um ciclo musical unificado.

Nos contrafacta, algo semelhante ocorria quando uma mudança apenas de texto permitia uma canção profana tornar-se coral luterano: "Innsbruck, Ich muss dich lassen", a saudade da cidade posta acima do consolo de todas as mulheres, virou "O Welt, Ich muss dich lassen", todo espírito. Os exemplos ainda se multiplicavam quando música Tupinambá colhida por Jean de Léry, considerada satânica pelo calvinista, por uma simples harmonização de Gabriel Sagard (entre 1621 e 1632) se prestaria à catequese católica dos Micmac, no Canadá (Veiga, 1981, p.242-247).

As paródias também revelam o quanto pode se tornar pequena a separação entre música sacra e música secular, mesmo distinguindo-se música litúrgica (oficialmente prescrita) de música religiosa (mais livre). Ainda poderíamos cogitar de música de festejos populares remotamente vinculados à religião. É o caso dos reisados nordestinos em relação ao ciclo religioso natalino, por exemplo. Na Bahia, o Senhor do Bonfim tanto faz música quanto faz política. Em outro extremo, magníficas obras sacras do Romantismo (Berlioz, Liszt, Verdi) estão totalmente fora de proporção com os serviços. Concílios e bulas papais cuidaram de prescrever o apropriado. ${ }^{6}$

No caso das religiões afro-brasileiras, outro aspecto da relação entre música e religião tem realce. Na realidade, há culturas africanas em que música e participação na música são indispensáveis em qualquer aspecto e status da vida social.

${ }^{6}$ O Motu Próprio “Tra le sollecitudini”(1903) de Pio X (18351914), franciscano afeito aos trabalhos pastorais, posteriormente santificado, era uma das faces do catolicismo oficial. Versa sobre a música sacra, com 29 instruções rigorosas agrupadas sob princípios gerais, gêneros, textos litúrgicos, forma externa das composições sacras, cantores, órgão e instrumentos (o piano proibido, bandas excluídas das igrejas), extensão, meios principais. Uma das recomendações é a de restabelecimento das Scholae cantorum, o que Guilherme de Melo seguiu no Colégio São Joaquim, em Salvador. É previsível um reflexo na música secular pelas restrições, ainda mais a dos recursos de execução. O Motu próprio sobre a música sacra, acrescido da Constituição apostólica 'Divini cultus' sobre liturgia, canto gregoriano e música sacra, de Pio XI (18571939), ainda era publicada no Brasil em 1951. 
H.J. Kwabena Nketia, outro de meus mais caros mestres e dos mais iluminados, ele próprio um Akan de Gana, nos ensinava que nem ao Ashanti-hene, autoridade suprema e homem idoso, era permitido não participar da dança, o que era mitigado por um gesto ou aceno que indicasse sua participação. A questão do transe é estudada em profundidade pelo etnomusicólogo Gilbert Rouget, numa tentativa de esboçar uma teoria geral sobre música e possessão. La musique et la transe é sua obra principal, em segunda edição revista e ampliada de 1990. A edição anterior (1980) foi premiada pela Academia Francesa. Recebeu uma resenha crítica de Andras Zempléni em L'Homme (1981, p. 105-127).

Rouget distingue o transe do êxtase, embora haja casos, como o de Teresa d'Ávila, em que ela passava de um a outro. Rouget elabora duas séries de características diferenciais entre o transe e o êxtase: imobilidade, silêncio, isolamento, ausência de crise, privação sensorial, relembrança, alucinação, de um lado (êxtase); movimento, ruído, sociedade, presença de crise, superativação sensorial, amnésia, normalidade, do outro (transe). Dei realce a "silêncio" e "ruído", embora esse não seja termo genericamente adequado para música.

Para o transe, Rouget distingue o induzido do conduzido, o "musicante" (xamãs) do "musicado" (iniciados). As questões que levanta entre música e possessão são múltiplas. Quando a música atua? Que música? Que ela significa? Quem a faz e em que estado? Quais as relações entre músicos e possessos? Quais entre dança e música? Quais as estruturas de consciência? Quais as relações com os deuses e com a cura? O que Rouget conclui do inventário que faz é que as relações entre música e transe são de extrema variedade. Um documento fascinante que ele apresenta é uma carta de um jovem etnomusicólogo de Benin, em visita a Paris, narrando ao amigo Asogba sua experiência de assistir a uma ópera. "Com certeza", disse ele, "as diferenças são imensas. Não impedem! Sustento que fundamentalmente uma representação em l'Opéra e uma festa de vodu em Benin são sob muitos pontos de vista totalmente comparáveis." (Rouget, 2008, p.434). Rouget, ao que tudo indica, concordou com ele. Pode-se conversar com deuses suando, como ocorre em nosso Candomblé. Pode-se conversar com eles no silêncio ou no uníssono de uma melodia gregoriana. Talvez o toque do adarrum seja um tipo de "uníssono" em meio à rica polirritmia e polimetria da música e dança do Candomblé, precipitando o transe.

Etnomusicólogos e antropólogos falam de universalismo (algo a ver com a busca de leis gerais, a tendência nomotética), mas falam também de relativismo cultural (a tendência idiossincrática oposta: o certo é o que o outro diz que é, não o que penso ou observo com meus olhos, de fora); falam também de perspectivismo (uma multinaturalidade que assume, para um mesmo fato ou objeto, interpretações diversas da mesma coisa).

\section{DE DIVISIONE NATURAE}

Distinguem-se caminhos de salvação (predominantemente orientais) de religióes propriamente ditas, como as abraâmicas. Essas, entre outras, estabelecem comunidades das quais se deve pertencer para que se alcance (ou não) a salvação, enquanto as primeiras cuidam de escapar do ciclo da vida por se alcançar uma liberação final, ou chegar a um nirvana onde se deixe finalmente de ser. "Ser ou não ser", sempre a questão. "Relegere" (observar cuidadosamente) e "religare" (ligar novamente) podem estar na etimologia latina de nosso termo religião. Porque mínima, uma definição de Friedrich Schleiermacher (1768-1834) pode ser adequada ao recuo no tempo pretendido: "A religião é um sentimento ou uma sensação de absoluta dependência" (apud Gardner; Hellern; Notaker 2005, p. 19).

Ora, para que um sentimento ou sensação de dependência se tornem conscientes, mesmo em seu estado mínimo, o pressuposto é que o ser vivo já tenha consciência de estar vivo. Já é ele e algo outro que não ele. Nenhum sentido no mundo é inato, ou anterior, mas o que deriva da experiência. O Homo sapiens, assim, terá despertado de um estado arcaico (de sono profundo, por analo- 
gia) em sua complexa evolução para estruturas de consciência em que, gradativa e cumulativamente, desenvolve um ego que o separa e afasta da natureza. ${ }^{7}$ Essa separação geradora de tensões não é apenas virtual. Estamos tratando com fenômenos psicofilogenéticos que são físicos e biológicos, além de mentais, geradores de necessidades. Não é justo atribuir a "abelhudês” de Eva (ou Evas?) a um acaso. Mas o pecado capital que continuou cometendo, o querer-saber, metaforicamente, nos tirou do Éden.

Religião e ciência compartilham virtudes na busca de uma última causa; a ciência, mais recente, para escapar de uma cadeia interminável de causas e efeitos a que esteve condenada por um pensamento linear newtoniano. Vistas de longe pelos músicos, mais uma vez, as fronteiras entre o espiritual e o material se esmaecem. Se tomarmos um acarajé a esmo, para decompor seus elementos constitutivos, um pão de queijo mineiro, ou um jenipapo (que daríamos a Eva se houvesse uma versão tropical do mito do Gênesis), iríamos dos materiais de que são feitos às tecnologias que os produzem e sem as quais não chegariam à nossa mesa, até significados tais como a de oferendas a Exu (acarajé), pintura corporal de índios amazônicos (jenipapo) ou gulodice exportável para gordinhos incuráveis (pãezinhos congeláveis), respectivamente.

Milan Kundera, tcheco de nacionalidade cassada e livros proibidos, apoia uma iluminação poli-histórica da existência em seus romances, para o que precisa dominar a técnica das elipses, a arte da condensação, senão cai na armadilha da duração interminável. Indagado sobre as sete partes de uma de suas obras, que poderiam ter sido sete romances diferentes, de tamanho razoável, explicou que, se as tivesse feito menos elíticas, teria perdido o mais importante: não teria sido capaz de captar, num só livro, a "complexidade da existência humana no mundo moderno”. O “moderno” é dispensável.

Há, assim, uma escala de visões complementares de foco variável. O olhar do cientista é aguçado pela necessidade de resolver problemas.

${ }^{7}$ As estruturas de consciência propostas por Jean Gebser influenciam este trabalho.
O do humanista pode ser mais abrangente e apenas buscar configurações, sem compromisso com progresso e resoluções. Ambos, entretanto, estão limitados pelos próprios sentidos e circunstâncias que os cercam.

A audição e suas extensões, assim como a percepção musical que ocorre no tempo e requer memória, merecem mais atenção. ${ }^{8}$ Os subsistemas que pensamos como música são construções e projeções do sentido da audição, mas não só, como esquematizaremos mais adiante. Esse sentido tem bases biológicas evolutivas, psicológicas, sociais e culturais. Ouvidos não têm pálpebras, deu-se conta Quignard. Ouve o bebê desde o quarto mês no ventre da mãe (ontogenia, filogenia); ouvimos mesmo quando dormimos; ouvem até os surdos à sua maneira (Helen Keller, implantes de cóclea, ouvido interior, musicofilia). Fruto da mesma faina que outros sentidos do homem compartilham para fazêlo sobreviver, a audição tem, portanto, peculiaridades. Assim também a fala, com a qual partilha, muitas vezes, do aparelho fonador.

É possível tratar de música e de tradições musicais de modo restritivo, ainda que impelidos pelo que retratem em si dos homens e mulheres que as geraram. Encontraríamos continuidade da mudança e apenas potenciais reflexos de valores, estruturas e funções distintos, sem exame dos vínculos. A sustentabilidade de repertórios, ainda que importe muito, é realmente secundária e até caprichosa..

Se do homem é de que tratamos, entretanto, passamos à complexidade imensa de sistemas dentro de sistemas, dentro de sistemas, música em toda sua variedade no tempo e no espaço, apenas um desses sistemas interligados e interdependentes. $\mathrm{O}$ modelo cibernético que se segue é uma simplificação (Figura 1) reproduzida de L.L Langness com pequenas alterações (2005, p. 261). A ideia é a de um sistema fechado, em que tudo afeta tudo por um complexo sistema de feedbacks, pelo qual um

${ }^{8}$ Inclua-se uma negligenciada e necessária higiene auditiva: a surdez decorrente de poluição sonora e de audição continuada de sons e ruídos acima do limite de segurança $(85 \mathrm{Db})$ já atinge um terço da população brasileira (dados desatualizados, de 2002). Além de não saberem disso, as vítimas não encontraram apoio oficial, uma vez que nosso país ainda não considera surdez como problema de saúde pública. 
controle é estabelecido. Poder-se-ia pensar também do universo como um organismo à maneira da hipótese de Gaia, embora controversa, do ponto de vista da ecologia profunda.

Figura 1

\section{MODELO CIBERNÉTICO}

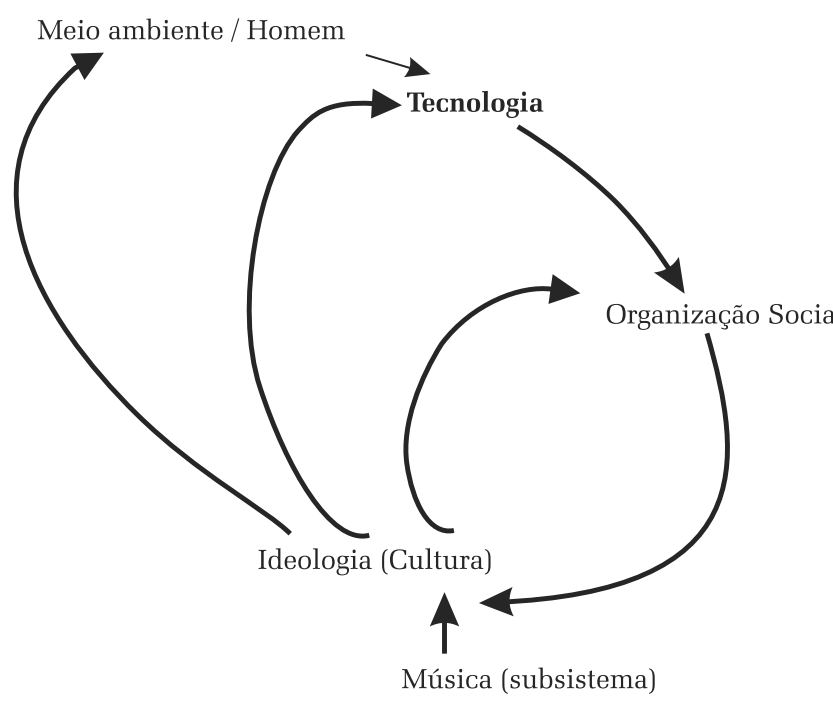

típicos dos primeiros evolucionistas e difusionistas. Tampouco o relativismo cultural pode ser aceito sem limites diante de situações de vida ou morte. A lista de disfunções, por sua vez, não é apenas brasileira, mas se manifesta nas mais diversas partes do mundo, no passado e no presente. ${ }^{9}$ Há indicações de que fomos canibais em nosso passado, como também nossos parentes geneticamente mais próximos, os chimpanzés.

Não nos adiantaria muito olhar aqui para um céu de mais de quatro e meio bilhões de anos, ainda mais considerando que a luz das estrelas e astros que nos chega, tal as distâncias siderais percorridas, pode vir de corpos que nem mais existem. Tudo acaba, inclusive as civilizações. Deixando em paz astronomia e astrofísica, temos ainda de aplicar redutores no retrocesso à escala dos hominídeos que nos antecederam, na busca do Homo musicus e, quiçá, do Homo humanus. Esqueçamos Lucy, com seus

Singularizando a música, colocando-a no centro, o seguinte modelo inspirado em Foucault (1995, p. 372-384), detalha três interfaces correspondentes às "ciências" que, a seu ver, percorrem as regiões epistemológicas de domínio das ciências humanas (Figura 2):

Figura 2

\section{À la Foucault}

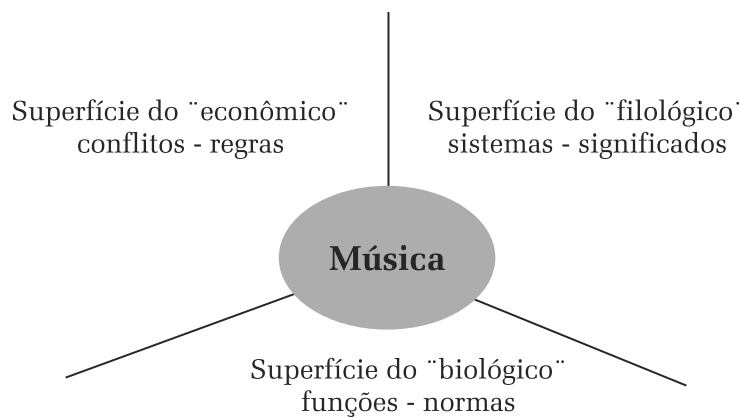

A Antropologia tem mantido com altos e baixos, repúdios e resgates, pelo menos cinco conceitos-chave: as ideias de evolução, de cultura, de estrutura, de função e de relativismo (Perry, 2003), mas não o tipo de evolução linear e o determinismo, possíveis milhões de anos (quatro?), sem ignorar tampouco a labuta dos paleontólogos e arqueólogos. Seria insensato, entretanto, não recuarmos aos milênios mais recentes (setenta a cinquenta?), em que nossos ancestrais diretos aprenderam a organizar sons humanamente e articulá-los em símbolos. Esse é o ponto crucial da humanidade.

Embora ainda haja controvérsia entre os especialistas, a evidência fóssil tem crescido a cada ano, mas sem muita divergência sobre o curso geral dos eventos (Langness, 2005, p. 248-249). O volume de cérebro esteve envolvido, mas não mais explica artefatos como depen$t \neq 0$
(processos) dência disso. Isto é, a relação entre tama$t=0 \quad$ nho do cérebro como distintivo para os (estruturas) humanos e sua cultura foi abalada: a capacidade de "proto-humanos" bípedes,

${ }^{9}$ Senicídio ou geronticídio, sacrifícios humanos, suicídio, suicídio cultural, sati (prática de sacrificar viúva na pira funerária do marido), eutanásia involuntária e voluntária, suicídio assistido, assassinatos, genocídio, violência e guerra, o que faz insistir um conceito de saúde cultural, cujos parâmetros de avaliação seriam os mesmos da saúde mental. 
eretos, de cérebro relativamente pequeno fazerem artefatos ficou comprovada claramente e recuou centenas de milhares senão milhões de anos antes do que anteriormente se pensava. Não se pode saber exatamente quando o fogo foi primeiro usado, ou uma verdadeira linguagem, ou quem concebeu a primeira cerimônia funerária, ou o que seja, mas há pouca dúvida de que, por alguma razão, uma grande irrupção de criatividade e atividade inovadora ocorreu entre 40 ou 50.000 anos atrás, o que pode ter sido o resultado de uma mudança menor, mas significativa, no cérebro humano. Aparentemente, as relações biológicas e culturais do homem, cujas formas e comportamentos de origem haviam evoluído juntos, lentamente, lado a lado, se alteraram: a evolução fundamental na mudança do corpo cessou, enquanto a evolução comportamental (cultural) se acelerou dramaticamente. Alguns recuam esses sinais até 60.000 anos atrás (Blainer, 2012, p.12) e pelos 30.000 anos seguintes. Estudiosos da Pré-História e arqueólogos referemse a esse despertar da humanidade como "O Grande Salto à Frente” ou “A Explosão Cultural”. Seja que nome se dê, ele é ainda um grande enigma.

\section{USOSE FUNÇÕES}

Um breve comentário sobre questões de usos e funções de música cabe aqui. Preocupados com o belo, é relativamente fácil esquecer a utilidade e a necessidade das artes em sua concepção; mais ainda no caso de música, fenômeno no tempo, fundamentalmente não representacional. Queremos saber não somente o que música é, mas o que faz para as pessoas, como os acarajés, os pãezinhos mineiros e os jenipapos.

Teorias de cultura caducam, mas não desaparecem de todo. Malinowski (1884-1942) destacou “descanso" (relaxation) como uma de suas sete necessidades biológicas básicas individuais. Dela sistemas de jogo e repouso derivam como respostas diretas, isto é, organizadas, coletivas. Uma necessidade instrumental de renovação de pessoal lhe corresponde, atendida pela educação, como respos- ta. ${ }^{10}$ Tudo isso está no bojo de necessidades mais amplas de natureza simbólica e integrativa, tais como transmissão de experiência por meio de princípios precisos e consistentes (conhecimento), meios de controle intelectual, emocional e pragmático do destino e do acaso (mágica, religião) e ritmo comunitário de recreação, exercício e repouso (arte, esportes, jogos, cerimonial). Designou essas três categorias como "Sistemas de Pensamento e Fé".

Uma das críticas ao esquema funcional descrito acima (apud Langness, 2005, p. 97-103) não é apenas ao caráter estático da explicação de algo que muda, no funcionalismo psicológico, dito também “puro", e a constatação de disfunções. Uma das limitações severas do esquema é limitar as artes à recreação. Divertimento é um dos casos em que uso e função podem se achatar numa indignidade só. ${ }^{11}$

Alan P. Merriam (1923-1980) foi o primeiro a abordar usos e funções na antropologia da música, fazendo, em adição, uma distinção entre eles. Em sua obra clássica, explica que “"uso' [...] se refere à situação em que música é empregada em atos humanos, enquanto 'função' diz respeito às razões para seu emprego e particularmente à finalidade mais ampla que serve.” (Merriam, 1964, p. 210).

A quantidade de usos é enorme. A de fun-

10 Mais uma vez a perspicácia de um poeta diz tudo e diz melhor. "O Poema da necessidade" de Drummond, da coletânea Sentimentos do Mundo, resume: "É preciso casar João / é preciso suportar Antônio, / é preciso odiar Melquíades, /é preciso substituir nós todos. // É preciso salvar o país, / é preciso crer em Deus / é preciso pagar as dívidas / é preciso comprar um rádio, / é preciso esquecer fulana. // E preciso estudar volapuque, / é preciso estar sempre bêbado, / é preciso ler Baudelaire, é preciso colher as flores / de que rezam vários autores. // É preciso viver com os homens, / é preciso não assassiná-los, / é preciso ter mãos pálidas / e anunciar o FIM DO MUNDO. (Meus realces. Entendo “comprar um rádio” como ouvir música e notícias).

${ }^{11}$ Theodor Adorno (1903-1969), partindo de uma vivência de música radical e séria (foi aluno de Alban Berg e de E. Steurmann) comenta: "O aceite de que esta função [única de música] seria justo a do entretenimento não basta. Caberia ainda perguntar como alguém que não sabe absolutamente o que é, seja sob a ótica da consciência, seja do ponto de vista do inconsciente, pode simplesmente ser entretido? O que quer dizer afinal de contas entretenimento?” (2011, p.113; 1976, p.39). Mesclei a tradução da edição americana com a brasileira, para tornar a passagem mais legível. Adorno repetidamente expressou sua preocupação com a indústria cultural e seus efeitos. Não gostava do termo "música de massa", para que não parecesse uma criação autônoma das massas, em vez de uma imposição dos poderes dominantes. 
ções, Merriam prefere associar à questão dos universais em música, adotando o quarto dos sentidos de função dados por Siegfried. F. Nadel ${ }^{12}$ como "a eficácia específica de qualquer elemento pelo qual ele preenche os requisitos de uma situação, isto é, responde a uma finalidade objetivamente definida; isto é a equação de função com finalidade[...]" (apud Merriam, 1964, p. 218). Merriam passa, então, a caracterizar dez funções: expressão emocional, gozo estético, entretenimento, comunicação, representação simbólica, resposta física, reforço da conformidade a normas sociais, validação de instituições e rituais religiosos, contribuição para a continuidade e estabilidade da cultura, contribuição à integração da sociedade (1964, p. 223-227).

Nettl responde a Merriam com algumas inquietações (1983, p. 149-153). Considerando a amplitude e a diversidade das funções, sugere agrupá-las. Representação simbólica, conformidade às normas, continuidade, estabilidade e integração cultural poderiam ser reunidas na afirmativa de que "música funciona como expressão simbólica dos principais valores, padrões ou temas de uma cultura" (p. 150). Num procedimento comparativo que tentou entre seis culturas distintas, com as quais tinha tido convivência, excluiu "comunicação", pela dificuldade de avaliação, e constatou a presença das nove demais funções em graus distintos, que aferiu subjetivamente de 1 a 5 (p. 162). Passou, então, a propor dois modelos teóricos dos quais nos interessa o que ele chama de "A pirâmide" (p. 157-161). Nesse modelo, coloca os usos na base e procede como "um contínuo que move dos mais absolutamente pé-na-terra e factuais aos mais vitalmente interpretativos e assim talvez não comprováveis" (p. 157). O topo da pirâmide é uma abstração na qual os membros de uma determinada cultura poderiam divergir entre si e do observador de fora: problemas epistemológicos do êmico/ético (Cf. Harris, 1999, p. 31-48). Não obstante, a "confissão" de Nettl (p. 159) não é fruto de uma postura superficial: "A função de músi-

\footnotetext{
${ }^{12}$ É o mesmo autor cujo artigo de 1930 eu cito, mas não tive acesso à obra referida por Merriam: S. F. Nadel, The foundation of social anthropology (1951).
}

ca na sociedade humana, o que ela faz em última instância”, diz ele,

é controlar o relacionamento da humanidade com o sobrenatural, mediando entre pessoas e outros seres, e dar suporte à integridade de grupos sociais individuais. Faz isso expressando os valores centrais da cultura de forma abstrata.

Apesar das substanciais atualizações e revisões que Nettl faz na edição recente de sua importante obra (2005), o capítulo correspondente ao anterior sobre usos e funções elimina o quadro comparativo das funções, mas se enriquece e se torna mais claro sem mudar a concepção dos dois modelos.

Retornemos a Siegfried F. Nadel (19031956), que conseguiu ser músico, filósofo, psicólogo e antropólogo. Seu artigo "The Origins of Music" mereceu ser traduzido por Theodore Baker (1851-1934), pioneiro autor do primeiro grande trabalho sobre música de índios da América do Norte. Diz Nadel:

Achamos evidência especial em apoio à opinião de que música foi um produto do propósito do homem de criar para seu próprio uso uma linguagem mágica peculiar de invocação e exorcismo" (1930, p.542, meu realce). ${ }^{13}$

Nadel não diz de que "evidência especial" se trata, mesmo que a impressão de um forte vínculo entre religião e música seja amplamente compartilhado. Quanto a não ser natural, mas um produto intencional do homem, o que é provável, cabe lembrar que uma recombinação de elementos que já existam é a base da maioria das inovações. Nadel afirma também que "Arte não permanece para sempre limitada pelo culto. A partir destas manifestações mais antigas ela cresce para um novo estado, independente; faz para si mesma novas leis para sua própria vida” (1930, p. 543, meu realce). ${ }^{14} \mathrm{Tam}$ bém é possível, mas a independência total é uma

13 "We find special evidence in support of the opinion that music was a product of man's purpose to create for his own use a 'peculiar' magic language of invocation and exorcism"

14 "Art does not remain forever bounded by the cult. Out of these earliest manifestations it grows into a new, independent estate; it makes unto itself new laws for its
own life" 
ilusão. Nem instrumentos musicais são puramente objetos, mas, antes, produtos da confluência de dois tipos de fluxos. De um lado estão crenças (sempre envolvidas na origem dos instrumentos) e simbolismos, com reflexos sociais e desenvolvimento histórico. De outro lado, em direção oposta, música, técnica (determinantes corporais) e, finalmente, execuções que convergem no instrumento musical propriamente dito. Por isso mesmo, a organologia não despreza um único detalhe dessas interfaces, por serem significativas e donde as descrições e classificações procedem.

A música, evidentemente, tem dificuldades muito maiores do que as artes visuais nos registros arqueológicos. Mesmo no esplendor da pintura rupestre, em Trois Frères (Ariège), tornada famosa pelos estudos e pela tenacidade do Abade Henri Breuil, uma representação de um ser humanoide (rara, apenas duas), semi-humano, semianimal, é descrita como "um 'feiticeiro' da Idade da Pedra Tardia tocando arco musical”. É também a interpretação do musicólogo francês Jacques Chailley (1985, p. 1), que lhe atribui 15.000 anos. Para outros, estaria tocando um instrumento tubular de sopro. Na realidade, não dá para dizer, embora a diferença de classificação seja enorme. São apenas $30 \mathrm{~cm}$ de altura dessa figura, que tem cabeça de bisão, pernas humanas e braços teriomórficos com mãos como pezinhos. Parece dançar, avançando por trás de animais também híbridos: um cervo de patas talvez de palmípede e um bisão com os quartos traseiros de cervídeo fêmea, e que revira a cabeça como se olhasse para o feiticeiro. Muito detalhe para muita dúvida. O que desperta alguma certeza é a de relação do instrumento com um ritual de mágica.

A flauta mais antiga já descoberta pode ser a assim chamada "flauta de Divje Babe", encontrada na caverna eslovena Divje Babe I, embora isso seja controvertido. É um fragmento do fêmur de um urso de caverna, datado de cerca de 43.000 anos. No entanto, se é um instrumento musical ou simplesmente um osso mastigado por um carnívoro tem sido um debate aberto. Em 2012, duas flautas que haviam sido descobertas na caverna de
Geißenklösterle (Suábia), receberam um novo exame de datação de carbono de alta resolução, produzindo uma idade de 42.000 para 43.000 anos. ${ }^{15}$

Um dos velhos artefatos tido, sem dúvida, como um instrumento sonoro (não necessariamente musical) é uma flauta ou apito, datada de aproximadamente 30.000 anos, relacionada aos CroMagnon, no sítio arqueológico de Dolni Vestonici, na República Tcheca. Roland de Candé (2001, p. 44-45) ilustra quatro outros da mesma categoria organológica (aerofones): uma flauta de osso do perigordiano superior (Pair-non-Pair) e dois apitos, ambos magdalenianos de Roc de Marcamp (Gorgogne). O quarto é um aerofone livre, um zumbidor, também da época magdaleniana, de La Roche de Birol. ${ }^{16}$ Embora haja um complexo de fatores a ser considerado, a conclusão que se pode tirar é a da possibilidade de existência de música no paleolítico superior, há pelo menos 40.000 anos, bem antes da revolução neolítica.

Não se pode concordar com a afirmação que Nadel faz em continuação à citação anterior:

Semelhantemente, também, ela [a arte] deve crescer numa linha direta e ininterrupta da lei que determina os primeiros inícios de arte, os princípios que se aplicam à totalidade da arte evolucionária, à arte como a apreendemos hoje (1930, p. 543, meu realce).

Mesmo que, em 1930, Nadel já se distanciasse dos preconceitos etnocêntricos de um Waldo S. Pratt (1857-1939), algo ainda resta aí. Pratt foi a figura que institucionalizou a disciplina de Musicologia para os falantes de língua inglesa, em

15 O verbete "Paleolythic flutes" da Wikipedia tem duas excelentes reproduçóes das duas flautas. A simetria dos dois (?) furos restantes da flauta Divje Babe não parece indicar acão de feras. Acesso em 25.06.2013, no endereço http://en.wikipedia.org/wiki/Paleolithic_flutes.

16 Os zumbidores são aerofones livres. Produzem som pela ativação do ar circundante, isto é, não contido em um tubo ou vaso globular, como nos instrumentos de sopro propriamente ditos. Nesse caso, um rombo (não raro com formato de peixe) revolve em torno de si e rodeia no ar atado à mão do executante por uma linha ou fibra. São antiquíssimos, do ponto de vista da difusão, com uma configuração que os assinala geograficamente dispersos pelo mundo, já sem indícios de contato que o tempo apagou. Não raro estão associados a ritos de iniciação de jovens rapazes e são tabus para as mulheres. Como também ocorre, o caráter ritual se degrada e instrumentos de tal antiguidade aparecem como brinquedos de criança, como nosso berra-boi. 
1915. Nãolhe faltaram seriedade e erudição. Na obra enciclopédica que publicou como um guia para o estudo de história da música, em edição revista contemporânea do artigo de Nadel (a edição princeps é de 1907), trata de música antiga como não civilizada; música indiana e chinesa, entre outras, como "semicivilizadas", mesmo incluindo ilustrações de ricos instrumentos dessas e de outras civilizações (Pratt, 1930). ${ }^{17}$ Vai longe demais, num evolucionismo unilinear e num determinismo que caducaram, além do evidente etnocentrismo.

Como estamos buscando critérios para ir às origens, a obra magna de Henri Gebser (1905-1973) pode ajudar nas conjecturas sobre o tempo e nas articulações. Poucos terão reunido subsídios de tantas disciplinas quanto ele (Quadro 1). Na ausência de datações científicas precisas, as estruturas que propõe podem ajudar a superar os vazios da documentação pré-histórica. As tabelas sinópticas, apresentadas ao final de sua obra principal, The EverPresent Origin, contêm dezessete colunas distintas, seis delas subdivididas de dois a sete tópicos (Gebser, 1985). A seleção que segue é de Georg Feurstein (1987, p. 20) à qual acrescentei uma das colunas do original relacionada às formas de expressão. As traduções correm por minha conta.

O texto do grande pensador e historiador da cultura é de leitura difícil, crivado de neolo- gismos sutis e de etimologias. O esforço deve ser creditado a H. J. Koellreutter, que nos falava dele, malgrado o desconforto que nos causava. As estruturas de consciência de Gebser, cumulativas, tidas como mutações, parecem-me resoluções temporárias e sucessivas do polinômio gráfica e simplificadamente esboçado (Figura 1): $\sum[$ natureza + homem $] \longleftrightarrow$ [tecnologia $] \longleftrightarrow$ [sistemas sociopolítico-econômicos] $\longleftrightarrow$ [culturais (música, artes, linguagens) e (ideológicos)] $\longleftrightarrow$ [detalhamento, muitos outros]. Nas estruturas de consciência em que terá sido possível a emergência de sentimentos religiosos, música e fala são as correspondentes ao mágico e ao mítico, um processo que terá levado milhares de anos, a par do desenvolvimento não linear do cérebro e do sistema neural, assim como das estruturas constitutivas do aparelho fonador.

\section{AS ORIGENS SEMPRE PRESENTES}

Durante muitas décadas o problema das origens de música foi deixado para a futura Etnomusicologia, então basicamente Musicologia Comparativa, germânica. A base desse legado vem das primeiras teorias culturais historicistas da Antropologia: o evolucionismo e o difusionismo.

Quadro 1

\begin{tabular}{|l|l|l|l|l|}
\hline $\begin{array}{l}\text { Estrutura de } \\
\text { consciência }\end{array}$ & \multicolumn{1}{|c|}{ Estados correlacionados } & \multicolumn{1}{|c|}{$\begin{array}{c}\text { Bases cognitivas } \\
\text { enfatizadas }\end{array}$} & $\begin{array}{l}\text { Modo de apreensão } \\
\text { da realidade }\end{array}$ & \multicolumn{1}{c|}{ Formas de expressão } \\
\hline Arcaica & Sono profundo & Nenhuma/Latência * & Originário & - \\
\hline Mágica & Sono & Emoção & $\begin{array}{l}\text { Identificaç ão pré - } \\
\text { racional }\end{array}$ & $\begin{array}{l}\text { Imagens gravadas, } \\
\text { Idolo, Ritual }\end{array}$ \\
\hline Mítica & Sonho & Imaginação & $\begin{array}{l}\text { Deuses, Símbolo, } \\
\text { Mistérios }\end{array}$ \\
\hline Mental & Desperto & Reflexão & $\begin{array}{l}\text { Abstração racional } \\
\text { (causal) }\end{array}$ & $\begin{array}{l}\text { Deus, Dogma } \\
\text { (Alegoria, Credo) } \\
\text { Método }\end{array}$ \\
\hline [Racional] & \multicolumn{3}{|c|}{ [Esta é meramente a forma deficiente da estrutura mental de consciência] } \\
\hline Integral & Transparência & $\begin{array}{l}\text { Integração a -racional } \\
\text { (a-causal) }\end{array}$ & $\begin{array}{l}\text { (Divindade) (Sinérese) } \\
\text { (Diafaneidade) }\end{array}$ \\
\hline
\end{tabular}

* Esta categoria no esquema de Gebser é formulada em contraste a processos cognitivos mais complexos das outras estruturas. Mas a estrutura arcaica poderia tamém ser dita como tendo sensação como sua base cognitiva.

Este diagrama é baseada na tabela sinóptica ao final de The Ever-Present Origin de Gebser, simplificado por G. Feuerstein.

17 "Similarly, too, it [art] must grow, in a plain and unbroken line out of the law that determine the first beginnings of art, the principles which apply to the entirety of evolutionary art, to art as we apprehend it today."

Diferiam fundamentalmente sobre a criatividade do homem, ilimitada para os primeiros, pouca para os últimos. De um lado (evolucionista), invenção 
repetida e independente: a ideia de que o mesmo aspecto cultural evolvesse da mesma maneira em mais de uma cultura (evolução paralela). Do ponto de vista oposto (difusionista), esses mesmos aspectos são inventados apenas uma vez e num só lugar, e daí se difundem em ciclos culturais (não áreas culturais que precisam ser contíguas e terem evidência de contato histórico). Dos primeiros vem a noção dos "primitivos" como nossos antepassados vivos. Deixados sozinhos, repetirão tudo, tal qual como nós fizemos, para alcançarem nosso alto grau de civilização... A criança pode também ser estudada como um primórdio desse adulto. Já os difusionistas estudavam a distribuição espacial de traços e complexos culturais, emanados de um centro e difundidos como se fossem ondas concêntricas de um grande lago que um distúrbio provocasse, mas que teriam de se ajustar às barreiras geográficas encontradas. Do estudo dessas configurações, ora mais compactas, ora mais dispersas, a "hipótese idade-área” permitia a conversão de espaço em tempo, à falta de testemunhos arqueológicos concretos. Essas duas teorias foram importantes para a história dos instrumentos musicais, bem como influíram nos sistemas de classificação organológica.

O chamado "método comparativo" assumia não raro uma conotação de generalização precipitada e audaciosa: um procedimento pelo qual diversas classes de fenômenos, considerados comparáveis sob vários critérios, são examinados para determinar semelhanças, diferenças e suas causas. O que emerge da Segunda Guerra Mundial como "Etnomusicologia" (no início dos 50) passou a criticar severamente esse método, pondo em questão o nível em que comparações musicais eram cabíveis; certamente não o de superfície. Por outro lado, desistia das generalizações.

O problema das origens da música exigia um conhecimento diversificado e amplo das culturas musicais do mundo, o que se esperava de seus estudiosos. Entre eles, destacou-se Curt Sachs (1881-1959). Suas publicações envolveram história mundial da dança (1937), história dos instrumentos musicais e organologia (1940), ascensão de música no Mundo Antigo (1943), estudo compa- rativo entre as artes (1946), ritmo e tempo (1953), as nascentes de música (1965). Essa última, The Wellsprings of Music (publicação póstuma por Jaap Kunst, com quem dialogava), é aquela em que sua erudição convive exaustivamente com a crítica ao comparativismo. Fala de "tumbling strains" e de "stepwise melodies", para as músicas mais remotas, de estilos logogênicos e patogênicos, pathos e ethos. Sempre respeitado, alguns de seus livros, entretanto, passaram a ser tidos com reserva pelos etnomusicólogos mais jovens.

Sachs não esteve sozinho na sua empreitada de chegar a uma visão abrangente da história da música e buscar origens. Marius Schneider (19031982), assistente de Erich Von Hornbostel no Berliner Phonogramm-Archiv, chegou a ser seu diretor. ${ }^{18}$ Fez transcrições para fins comparativos de mais de mil gravações fonográficas, em grande parte não publicadas. Walter Wiora (1906-1997) foi outro seguidor. Tentou também juntar leste e oeste e ampliar a escala do tempo, indo ao Paleolítico para as origens. Sua obra principal, The Four Ages of Music (1965), esboça idades da música em escala mundial, numa periodização original e espartana (pouco mais de duzentas páginas). $\mathrm{O}$ primeiro capítulo parte da pré-história, com a cultura de caçadores e coletores da Idade da Pedra, à busca de rituais religiosos e examina as características da música “elementar”. Dá também exemplos do que essa música pode ter sido, pela análise comparativa de música de povos isolados da atualidade. Ter uma ideia do que essas músicas remotas poderiam ter sido pode satisfazer nossa curiosidade, mas não é o problema principal.

Bruno Nettl, com seu admirável bom senso, continua incluindo as origens de música entre seus trinta e um problemas ainda sem solução, a despeito da aparente desistência dos etnomusicólogos de tratarem deles. Ele saiu de voga por várias décadas, após os cuidadosos estudos de Curt Sachs, Walter Wiora e Marius Schneider e suas aplica${ }^{18}$ Hoje, esse arquivo, parcialmente destruído na Segunda
Guerra e posteriormente reconstituído, é parte do depar-
tamento de etnomusicologia do museu etnológico de
Berlim, a mais importante instituição do mundo onde
registros etnomusicológicos, como sons e músicas tradi-
cionais de todo o mundo, são coletados e armazenados. 
ções do controverso método. Nossos antepassados vivos, povos “naturais” (Veddas de Sri Lanka, povos da Micronésia, pigmoides das terras altas da Nova Guiné, pigmeus do Congo, bosquímanos, lapões, certos povos indígenas da América do Norte e do Sul), à sua revelia ou não, já nos haviam dito o que puderam.

Esses estudos foram precedidos de especulações de Rousseau, Herder, Darwin, Herbert Spencer, Richard Wagner, Carl Buecher, Karl Stumpf. O interesse retorna agora por via de novos psicólogos, etólogos e de biomusicólogos. A Biomusicologia comparece, em seus vários ramos, como musicologia evolucionária (estudo das origens de música, "música" de animais, pressões evolutivas sublinhando evolução musical, evolução de música e evolução humana), neuromusicologia (áreas do cérebro envolvidas no processamento de música, processos neurais e cognitivos desse processamento, ontogenia da capacidade e habilidade musicais) e biomusicologia aplicada (usos terapêuticos). Permanecem os estudos comparativos dos usos e funções de música, da consideração das vantagens e custos do fazer musical, e da busca dos aspectos universais dos sistemas musicais e do comportamento musical. Em suma: fazem de tudo para desagradar os devotos sacerdotes da grande música, inclusive insinuar a possibilidade de que uma das razões para a existência de música tenha sido e seja assustar rivais ou aterrorizar hordas inimigas. Adeus abençoada harmonia... ${ }^{19}$

Nas pegadas de Hornbostel, Nettl faz uma significativa cirurgia na questão das origens, dividindo-a em três quesitos: 1 . Por que música se originou? 2. Qual foi, de fato, o processo pelo qual música foi posta pela primeira vez em existência? 3. Qual foi a natureza dos produtos musicais originais, ou primeiros, ou mais antigos? A necessidade de música, o primeiro quesito, é, a meu ver, o fundamental para explicar sua sobrevivência até os dias de hoje.

19 Sugiro o site "Comparative Musicology" (http:// www.compmus.org/key_issues.php Acesso em: 25 jun. 2013), para um quadro atual de análise comparativa para musicologia sobre cinco "key issues" ou grandes áreas Classificação, e, daí, Universais e Migrações; Evolução Biológica e, daí, convergência de todas para Evolução Cultural. As cinco se interconectam.
Para que música, se ela não serve para nada?

Nos duzentos mil anos em que o Homo sapiens evoluiu (poderia ser muito mais), seria possível que as origens fossem múltiplas, mas não muitas. A única conclusão a que parece se ter chegado é que o desenvolvimento do aparelho auditivo e fonador que música compartilha com a fala teria sido para a defesa, sendo o uso para música um subproduto. Isso pode explicar distinções importantes entre as duas linguagens. A espécie imbuída de musicofilia (Sacks, 2007, p.10-11), capacidade neural da espécie, talvez não seja a única (a Etologia tem de nos convencer disso). Em escala restrita, a etnografia de um determinado grupo tenta elucidar o que ele atribui como origem de sua música. Ajuda a entender melhor os indivíduos pelos repertórios de que participam, mesmo que sejam respostas parciais à questão do "porquê" da música.

\section{ALLELUIA E MISERERE}

Big birth! Big bang! Teorias sobre a origem da vida e do universo. Especular é preciso. Pó do pó, infinitésima partícula e maravilha num universo enigmático, alegria e dor, o homem inventou música para dialogar com deuses e encontrar dignidade. Erra muitas vezes. As variações que compõe são ora sublimes, ora ignóbeis. Religião, língua, música são coevas, são capacidades de organizar e de agregar. Também desorganizam e desagregam. Violência e guerra permanecem por toda parte. Quaisquer que sejam as variações, o tema será sustentabilidade e paz.

Nas humanas, ciências ou narrativas, a invenção de um Homo musicus lhes pode ser útil, a despeito do auditivo não estar privilegiado nas civilizações recentes. "Um rosto de areia na orla do mar”, disse Foucault (1995, p. 404), o homem inventado por intelectuais pode estar com o fim próximo (também por ser barulhento, ouvir e não escutar, vale acrescentar). Não importa muito, se os seus sósias dos milênios, de trajetórias tão difíceis, tiverem sucessores melhores. Uma "bolsa 
de substâncias químicas [que] nervosamente adquiriu vida” (Bryson, 2005, p. 299) também a criou, mas eis que ora fazem tudo para exterminá-la. Einstein e Freud se corresponderam sobre a guerra, sem solução. Talvez teólogos e musicólogos, com a ajuda de cientistas e humanistas, entre esperançosos e céticos, juntos, consigam explicar a deuses atônitos o que fizeram ou andam fazendo. Assim seja, sem blasfêmia.

Recebido para publicação em 27 de junho de 2013 Aceito em 02 de setembro de 2013

\section{REFERÊNCIAS}

ADORNO, Theodor W. Introdução à sociologia da música: doze preleções teóricas. Trad. Fernando R. de Morae Barros. São Paulo: Editora UNESP, 2011.

Introduction to the sociology of music. Trad. E. B. Ashton. Nova York: Seabury Press, [1962] 1976. Tradução de Titulo original: Einleitung in die musiksoziologie.

BLACKING, John. A commonsense view of all music. Cambridge: Cambridge University Press, 1987.

The biology of music making. In: MYERS, Helen (Ed. Ethnomusicology: an introduction. Nova York Londres: W.W. Norton, 1992. p. 301-314.

Music, culture, and experience: selected papers of John Blacking. Editado e com uma introdução de Reginald Byron. Urbana e Chicago, IL: University of Chicago Press, 1995. (Chicago studies in ethnomusicology)

BLAINEY, Geoffrey. Uma breve história do mundo. 2.ed. rev. atual. São Paulo: Editora Fundamento, 2012.

BRYSON, Bill. Breve história de quase tudo. Trad. Ivo Korytowski. São Paulo: Companhia das Letras, 2005.

CANDÉ, Roland de. História universal da música. Trad. Eduardo Brandão. São Paulo: Martins Fontes, 2001. 2 v.

CHAILLEY, Jacques. 40.000 ans de musique: l'homme à la découverte de la musique. Reedição revista. Plan-de-laTour, Provença: Editions d'aujourd 'hui, 1985.

CHATEAUBRIAND, François-Auguste. Génie $d u$ christianisme ou beauté de la religion chrétienne. Paris: Chez Migneret, 1802.

DEACON, Terrence W. The symbolic species: the co-evolution of language and the brain. Nova York: Norton, 1997.

FERGUSON, Marilyn. The brain revolution: the frontiers of mind research. Nova York: Bantam Books, 1975.

FEUERSTEIN, Georg. Structures of consciousness: the genius of Jean Gebser; an introduction and critique. Lower Lake, CA: Integral Publishing, 1987.

FOUCAULT, Michel. As palavras e as coisas: uma arqueologia das ciências humanas. Trad. Salma Tannus Muchail. İ 6.ed. São Paulo: Martins Fontes, 1995.

GALEFFI. Dante Augusto. Ética e complexidade: a emergência triética planetária. In: AZEVEDO, Eliane S. SALLES, João Carlos (Org.). Ética e ciência. Salvador: Academia de Ciências da Bahia, 2012. p.65-104.
GAARDER, Jostein; HELLERN, Victor; NOTAKER, Henry. O livro das religiões. Trad. Isa Mara Lando. Revisão técnica e apêndice de Antônio Flávio Pierucci. São Paulo: Companhia das Letras, 2005.

GEBSER, Jean. The ever-present origin. Trad. autorizada de Noel Barstad com Algis Mickunas de Ursprung und gegenwart [1949, 1953]. Athens, OH: Ohio University Press, 1985

GUERRERO, Angeles Gaviro; FRANCES, Peter (Ed). Prehistoric. Londres: Kindersley Dorling, 2009.

HARRIS, Mervin. Theories of culture in postmodern times. Walnut Creek, CA: AltaMira Press, 1999.

HOWELL, F. Clark et al. Early man. Nova York: Time-Life Books, 1976.

KHAZRAI, Houshang. A psicologia da música: uma reflexão atualizada. Cadernos de Pesquisa, São Luís, UFMA v.2, n.2, p.143-155, 1986. Disponível em: http:// tinyurl.com/ ov49vol. Acesso em: 16 jun. 2013.

LANGER, Susanne K. Filosofia em nova chave. Trad. e rev. Janete Meiches e J. Guinsburg. 2.ed. São Paulo: Perspectiva, 1959.

LANGNESS, L. L. The study of culture. 3.ed. rev. Novato, CA: Chandler and Sharp, 2005.

LEVMAN, Bryan G. The genesis of music and language. Ethnomusicology, v.36, n.2, p.147-170, 1992.

MAFFEI, Marcos (Ed.). Milan Kundera. In: . Os escritores: as históricas entrevistas da Paris Review. Trad. Alberto Alexandre Martins e Beth Vieira. São Paulo: Companhia das Letras, 1988. p.315-327.

MERRIAM, Alan P. The anthropology of music. Evanston, IL: Northwestern Universty Press, 1964.

MITHEN, Steven. The prehistory of the mind: the cognitive origins of art, religion and science. New York: Thames and Hudson, 1996.

NADEL, Siegfried. The origins of music. Musical Quarterly, v.16, p.531-546, 1930.

NETTL, Bruno. The study of ethnomusicology: twentynine issues and concepts. Urbana, Chicago, London: University of Illinois Press, 1983.

The study of ethnomusicology: thirty-one issues and concepts. Urbana and Chicago: University of Illinois Press, 2005. (Nova edição).

OSTERMANN, Lauro (Ed.) Pio X e Pio XI sobre liturgia e música sacra. 11.ed. Petrópolis: Vozes, 1951. (Documentos pontifícios, 22).

PERRY, Richard J. Five key concepts in anthropological thinking. Upper Saddle River, NJ: Prentice-Hall, 2003.

PRATT, Waldo S. The history of music: a handbook and guide for students. Fac-símile através Kessinger Publishing's Rare Reprints da edição revista. Nova York: G. Schirmer, [1907] 1930

QUIGNARD, Pascal. Ódio à música. Trad. Ana Maria Scherer. Rio de Janeiro: Rocco, 1999.

ROUGET, Gilbert. La musique et la transe: esquisse d'une théorie générale des relations de la musique et de la possession. 2.ed. rev. aum. Prefácio de Michel Leiris. Paris: Gallimard, 2008.

SACHS, Curt. The world history of the dance. New York: Norton, 1937.

The history of musical instruments. New York: Norton, 1940.

The rise of music in the ancient world: East and West. New York: Norton, 1943 
The commonwealth of the arts: style in the fine arts, music,and the dance. Nova York: Norton, 1946.

Rhythm and tempo. New York: Norton, 1953.

The wellsprings of music. Jaap Kunst, ed. New York: McGrow-Hill, 1965.

SACKS, Oliver. Alucinaç̃es musicais: relatos sobre a música e o cérebro. Trad. Laura Teixeira Motta. São Paulo: Companhia das Letras, 2007.

SANTOS, Maria Stella de Azevedo. Meu tempo é agora. 2.ed. Salvador: Assembleia Legislativa do Estado da Bahia, 2010.

SCHNEIDER, Marius. Primitive music. In: WELLESZ, Egon (Ed.) Ancient and oriental music. London: Oxford University Press,1957. p.1-82. (The New Oxford history of music, 1).

STORR, Anthony. Music and the mind. Nova York: Ballantine Books, 1993.
TRINDADE-SERRA, Ordep José. Rumores da festa: o sagrado e o profano na Bahia. 2.ed. Salvador: EDUFBA, 2009.

VEIGA, Manuel. Toward a brazilian ethnomusicology: amerindian phases. 2004. Tese (Doutorado in music) University of California at Los Angeles, UCLA. Facsímile in Ft. Manuel Veiga. SOTUYO, Pablo (Org.). Salvador: UFBA, 2004. p.56-423.

WAECHTER, John. Man before history. Nova York: E.P. Dutton [para Elsevier-Phaidon], 1976.

WIORA, Walter. The four ages of music. Trad. M. D. Herter Norton. Nova York: Norton, 1967.

WOLF, Josef et al. The dawn of man. Nova York: Harry N. Abrams Publishers, 1978.

ZEMPLÉNI, Andras. La musique et la transe. Resenha. L’Homme, v.21, n.4, oct./déc. p.105-110, 1981. 


\section{RELIGION AND MUSIC: variations in search of a theme}

\section{Manuel Vicente Ribeiro Veiga Junior}

Music relates to religion in a variety of ways, both in the belief systems or in the control of power. Both are culture universals. As we do not know music's own empirical universals, the comprehensive study of its association with the sacred is a double challenge. Concentrating on man and to understand him better, the search for origins held in common is an option. Though it is a process that de-emphasizes the musical monuments of religions proper and of the ways of salvation, Western and Eastern achievements will not be overlooked. Back to the remote past, the millennia that articulated humanly organized sounds into symbols are of a crucial importance. The angles, ideas, revisions, methods of approach to the lack of available evidence are the variations of our title. From an ethnomusicological perspective, the issues that have been brought back to life are neither about what kind of music was made, nor about the processes by which music was first created, but the reasons, i.e. the need for its existence (functions).

KeYwords: Religion and music. Origins and functions. Models. Instruments.

\section{RELIGION ET MUSIQUE: variations à la recherche d'un thème}

\section{Manuel Vicente Ribeiro Veiga Junior}

Musique se rapporte à la religion dans une variété d'aspects, soit dans les systèmes de croyance, soit dans le contrôle du pouvoir. Tous les deux sont des universaux de la culture. N'ayant pas connaissance des propres universaux empiriques de la musique, l'étude approfondie de son association avec le sacré est un double défi. En se concentrant sur l'homme et pour mieux le comprendre, on a pris l 'option, pour la recherche des origines possiblement communes, un procès qui ne met pas en emphase les monuments musicaux des religions proprement dites et des moyens de salut, les réalisations occidentales et orientales ne sont pas oubliées. Le retour vers le passé lointain, au cours de millénnaires où des sons humainement organisés sont articulés en symboles est d 'une importance cruciale. Les angles, les idées, les révisions, les méthodes d 'approche à l ' absence de données probantes disponibles sont les variations de notre titre. Du point de vue ethnomusicologique, les questions qui aujourd 'hui reviennent à la vie ne sont guère quel genre de musique a été fait, ni les processus par lequel la musique a été crée, mais les motifs, c'est-à- dire la nécessité de son existence (fonctions).

Mots-ClÉs: Religion et musique. Origines et fonctions. Modèles. Instruments.

Manuel Vicente Ribeiro Veiga Junior - Ph.D em Música (Etnomusicologia), Universidade da Califórnia (UCLA); BS e MS (Piano), Juilliard School of Music, New York. Professor emérito da Universidade Federal da Bahia (UFBA), colaborador na Pós-Graduação em Música. Membro da Academia Brasileira de Música e da Academia de Ciências da Bahia. Experiência na área de Artes, ênfase em Música, principalmente nas subáreas das ciências musicais (etnomusicologia, musicologia histórica), análise musical e música aplicada. Publicações recentes: Etnomusicologia brasileira e ética: a escuta ao índio, Ética e Ciência, Academia de Ciências da Bahia, p. 119-175, 2013; Sustentabilidade e música: uma visão enviesada, Música e Cultura (Associação Brasileira de Etnomusicologia), v. 8, n. 1, p.19-33, 2013; Musicologia brasileira: revisita a Guilherme de Melo, Atas do I Colóquio/Encontro Nordestino de Musicologia Histórica (PPGMUS - UFBA), p. 1- 24, 2012; Uma mesa-redonda do Primeiro Encontro da ABET em Belém. Música e Cultura (Associação Brasileira de Etnomusicologia), v. 6, p. 10-16, 2011. 